\title{
EFEITO DA APLICAÇÃO DE EFLUENTE DA FÁBRICA DE CELULOSE JUNTO COM FOSFOGESSO NA CORREÇÃO DA ACIDEZ DO SOLO ${ }^{1}$
}

\author{
T. KINJO'; R.I. SILVEIRA'; Z.Z. MARCOS²; I.O. ABRAHÃO²
}

RRSUMO: Foram coletados vários efluentes alcalinos da fábrica de celulose a fim de estudar a utilizaçăo destes junto com fosfogesso na correção da acidez do solo. Avaliou-se o poder de neutralização dos efluentes e a lixiviação de sódio na presença de fosfogesso numa coluna de terra. A aplicação do efluente eleva o pH do solo e o volume de efluente necessário para atingir pH 6,5 depende da sua composição química e o poder tampão de acidez do solo. A lixiviagăo de sódio é maior quando o fosfogesso é incorporado ao solo. A combinaçăo do efluente com o fosfogesso corrige a acidez do solo, aumenta o teor de cálcio e, ao mesmo tempo, reduz o acúmulo de s6́dio no solo.

Descritores: acidez do solo, efluente alcalino, lixivia negra.

\section{CBLLULOSE MILL LIQUID ALKALINE WASTE AND GYPSUM AS A SUBSTITUTE FOR LIME IN SOILS}

ABSTRACT: Alkaline liquid effluent from cellulose factories was used in an experimental study to appraise the feasibility of utilizing this material with industrial gypsum (residual material from superphosphate production) for the correction of soil acidity. A soil + gypsum column was prepared and leached with the sodium rich industrial waste. Soil pH was raised but the amont of material needed bring it to 6.5 was found to vary with soil chemical composition and soil acidity buffering capacity. The soil leachate was richer in Na when gypsum was presented. Results obtained show that industrial gypsum combined with alkaline waste neutralizes soil acidity, increases soil calcium content and prevents sodium accumulation in the soil.

Key Words: gypsum, soil acidity, alkaline waste.

\section{INTRODUÇÃO}

0 efluente de fábricas de celulose (lixivia negra) é um líquido residual de indústria. Esse líquido com reação alcalina tem, dentre outros elementos, o sódio como seu principal constituinte problemático. A composição química e alcalinidade do efluente varia com a natureza das atividades de indústrias que empregam processamentos diferentes na fabricação de celulose. A aplicação do efluente ao solo pode trazer uma série de modificações nas suas propriedades físicas e químicas e, consequentemente, afetar a produção agrícola. A elevação da porcentagem de saturação de s6́dio trocável no solo pode ocasionar um desequilibrio nutricional nas plantas e deterioração nas propriedades físicas do solo (Estados Unidos, 1954).

O acúmulo de sódio trocável depende da concentração de cálcio na solução do solo. KINJO \& MARCOS (1982b) mostram que, em solos do Estado de São Paulo, a relação sódio-cálcio trocáveis aumenta linearmente com a elevação da razão sódio-cálcio da solução do solo ou vice-versa. Uma maneira de aumentar o cálcio na solução do solo é a aplicação de fosfogesso, um resíduo industrial da fábrica de adubos. O cálcio é mais retido que o sódio pelos colbides do solo (FASSBENDER, 1975) e, consequentemente, o acúmulo de sódio no solo na presença de cálcio deve ser menor. Espera-se que a correção da acidez do solo

'Trabalho apresentado na 19" Reunião Brasileira de Fertilidade do Solo e Nutrição de Plantas, em Santa Maria-RS, de 23 a 27 de julho de 1990.

2 Departamento de Ciência do Solo, ESALQ/USP, Avenida Pádua Dias, 11 - Cxa.Postal, 09 - 13418-900PIRACICABA-SP. 
pelo efluente seja acompanhada pelo fornecimento de cálcio e enxofre pelo fosfogesso e a consequente lixiviação do s6dio.

O objetivo deste trabalho foi estudar a correção da acidez do solo com efluente da fábrica de celulose e a lixiviação de sódio na presença de fosfogesso.

\section{MATERIAL E METTODOS}

\section{Residuos industriais}

Os resíduos industriais utilizados no trabalho foram o efluente da fábrica de celulose e o fosfogesso da fábrica de adubos fosfatados.

Algumas características químicas dos efluentes coletados de várias fábricas estão apresentados no Quadro 1. São líquidos de alcalinidade apreciável e com teores elevados de sódio que podem causar deterioração nas propriedades físicas do solo. $O$ efluente $n^{\circ} 5$ foi o escolhido para o estudo de lixiviação do sódio no solo.

o fosfogesso, outro resíduo industrial, foi obtido da fábrica de adubos Ultrafértil. Sua composição química foi a seguinte: $\mathrm{CaO}=28,7 \%$; $\mathrm{SO}_{3}=43,3 \%$; $\mathrm{P}_{2} \mathrm{O}_{5}=1,2 \%$; Umidade $=12,7 \%$.

\section{Solos}

Os solos utilizados foram Latossolo Roxo, distrofico e Area Quartzosa, ambos localizados no Município de Piracicaba do Estado de São Paulo. Os solos foram escolhidos por serem ácidos e com valores de CTC diferentes. As amostras de terra foram coletadas da camada superficial de 0 a $20 \mathrm{~cm}$ de profundidade $e$, após secagem ao ar, foram destorroadas e passadas por uma peneira com malha de $2 \mathrm{~mm}$. As características físicas e químicas das amostras de terra estão apresentadas no Quadro 2. No estudo de lixiviação do sódio no solo, apenas amostras de terra do Latossolo Roxo foram utilizadas.

\section{Curva de titulação potenciométrica}

As curvas de titulação potenciométrica foram obtidas através da medida de $\mathrm{pH}$ das suspensões contendo volumes diferentes de efluente. para isso foram colocados $10 \mathrm{~g}$ de TFSA em copos de boêmia. $O$ volume total de líquido para a suspensão de terra foi 80 $\mathrm{ml}$ para o Latossolo Roxo, distrófico e $25 \mathrm{ml}$ para a Areia Quartzosa. A fim de manter o volume do líquido constante, porem, variar o volume do efluente, adicionou-se água destilada ao efluente para completar o volume total do líquido indicado anteriormente. A suspensão de terra foi agitada três vezes durante três horas de repouso. A determinação do $\mathrm{pH}$ foi feita colocando-se o eletrodo de vidro no sedimento e o de referência na solução sobrenadante.

\section{Lixiviação de sodio numa coluna de terra}

A lixiviação de s6́dio do efluente $n^{\circ} 5$ na presença de fosfogesso foi estudada numa coluna de terra do Latossolo Roxo. A coluna de acrílico consistia de 10 anéis. Cada um destes tinha as seguintes dimensões: diâmetro interno de $2,2 \mathrm{~cm}$; altura de $2 \mathrm{~cm}$ e volume interno de $7,6 \mathrm{~cm}^{3}$. Os anéis foram numerados de 1 a 10, iniciando de cima para baixo na posição vertical. Um anel extra foi colocado acima do $n^{0} 1$ para receber o efluente. No fundo do anel $n^{\circ} 10$ foi colocado um disco de papel de filtro para evitar a perda de terra. A coluna, assim preparada, foi preenchida com $80 \mathrm{~g}$ de terra, tendo, cada anel, $8 \mathrm{~g}$ de terra. $O$ uso de pequenos anéis facilitou a análise de terra uma vez que não foi necessário separar uma certa quantidade de amostra para análise. Os resultados foram mais precisos que os obtidos de colunas maiores.

O experimento foi conduzido da seguinte maneira. Os anéis de $n^{\circ} 6 \mathrm{a} \mathrm{n}^{\circ} 10$ receberam apenas a terra e os $n^{0} 1$ a $n^{0} 5$, a terra misturada com fosfogesso. Os níveis deste foram $0,122,244,488 \mathrm{e}$ $610 \mathrm{mg}$ por coluna. Primeiramente, aplicou-se $80 \mathrm{ml}$ do efluente $n^{\circ} 5 \mathrm{e}$, em seguida, água distilada, coletandose o percolado em frações de $10 \mathrm{ml}$ até atingir $160 \mathrm{ml}$. $O$ percolado foi analisado para determinar as concentrações de sódio e cálcio. A coluna de terra foi seccionada por anel para as determinações de $\mathrm{pH}$ do solo e dos teores de sódio e cálcio.

\section{RESULTADOS E DISCUSSÃO}

\section{Poder de neutralização dos efluentes}

A alcalinidade dos efluentes varia conforme sua origem (Quadro 1) e, consequentemente, o poder de neutralização dos efluentes também, conforme mostram as curvas de neutralização potencionétrica apresentadas nas Figuras 1 e 2. No Latossolo Roxo, o volume aplicado ao solo para atingir pH 6.5 foi equivalente a aproximadamente $13.000 \mathrm{~m}^{3} /$ ha para o efluente $n^{0} 1 \mathrm{e}$ $1.400 \mathrm{~m}^{3} / \mathrm{ha}$ para o efluente $\mathrm{n}^{0} 7$. Esses dois efluentes têm valores extremos quanto ao poder de neutralização enquanto que os demais se situam entre esses dois. $O$ volume de um efluente para atingir o $\mathrm{pH} 6,5$ varia de um solo para outro, dependendo de seu poder tampão 
Quadro 1 - Características químicas dos efluentes coletados de várias fábricas de celulose do Estado de São Paulo.

\begin{tabular}{|c|c|c|c|c|c|c|}
\hline \multirow[t]{2}{*}{ Efluente } & $\mathrm{CE} \times 10^{3}$ & $\mathrm{pH}$ & $\mathrm{Na}$ & $\mathbf{K}$ & \multirow{2}{*}{$\begin{array}{c}\text { Alcalinidade } \\
\text { N } \\
\end{array}$} & \multirow{2}{*}{$\begin{array}{c}\mathrm{CaCO}_{3} \text { equiv. } \\
t / 1000 \mathrm{~m}^{3}\end{array}$} \\
\hline & \multicolumn{2}{|l|}{$25^{\circ} \mathrm{C}$} & \multicolumn{2}{|c|}{ ppm } & & \\
\hline 1 & 1,13 & 9,7 & 293 & 22 & 0,002 & 0,11 \\
\hline 2 & 1,89 & 7,4 & 449 & 21 & 0,005 & 0,26 \\
\hline 3 & 10,94 & 8,4 & 3082 & 17 & 0,012 & 0,62 \\
\hline 4 & 2,33 & 9,0 & 633 & 53 & 0,008 & 0,41 \\
\hline 5 & 8,10 & 10,2 & 1013 & 48 & 0,009 & 0,47 \\
\hline 6 & 6,32 & 10,8 & 1633 & 27 & 0,014 & 0,68 \\
\hline 7 & 8,96 & 11,5 & 1116 & 49 & 0,045 & 2,23 \\
\hline
\end{tabular}

Fábricas:

1 - Indústria de Papel e Celulose-SIMÃo

2 e 4 - Cia Suzano de Papel

3, 6 e 7 - RIPASA

5 - CHAMPION Papel e Celulose S.A.

de acidez. A areia quartzosa, com pequeno poder tampão, necessita aproximadamente a metade do volume de efluente aplicado ao Latossolo Roxo para atingir o mesmo pH 6.5 .

\section{Lixiviação de sodio numa coluna de terra}

A remoção dos íons sódio e cálcio, pela lixiviação, está apresentada graficamente na Figura 3. A lixiviação de sódio aumentou linearmente nos primeiros $80 \mathrm{ml}$ de percolado, e passou a ser curvilinear, diminuindo assintoticamente com o aumento de volume do percolado. A lixiviação do cálcio também teve um comportamento semelhante ao do sódio, porém em quantidade muito menor.

Comparando-se a lixiviação teórica de sódio, sem retenção no solo, com a do experimento, observouse uma certa quantidade de sódio retido no solo até a coleta de um volume do percolado igual ao do efluente aplicado. Se não houvesse ocorrido a adsorção de sódio no solo, a quantidade de sódio lixiviado em $80 \mathrm{ml}$ de percolado seria igual ao total aplicado como efluente. Segundo KINJO \& MARCOS (1982a), a adosrção de sódio ocorre em solos do Estado de São Paulo e sua magnitude depende da concentração. $A$ adsorção máxima de sódio nos solos estudados pelos mesmos autores variou de 1,30 a $3,17 \mathrm{meq} / 100 \mathrm{~g}$ de terra, quantidade essa menor que os valores de capacidade de troca cationica efetiva.

A aplicação de gesso ao solo foi eficiente na remoção de sódio. No tratamento com $610 \mathrm{mg}$ de gesso por coluna, o maior nível do experimento, a lixiviação de sódio foi quase total com a passagem de um volume de água correspondente ao efluente aplicado. Em outros níveis mais baixos de gesso, a remoção de sódio foi proporcionalmente menor e levaria mais tempo e mais água para eliminá-lo. $O$ gesso é comumente utilizado na recuperação de solos afetados pelo excesso de sódio na região árida e semi-árida (Estados Unidos, 1954).

As quantidades de sódio e cálcio retidas no solo, após passagem de $80 \mathrm{ml}$ de efluente e o mesmo volume de água, estão apresentadas no Quadro 3. Os dados obtidos por 8 gramas de terra por anel foram recalculados por 100 gramas de terra. $\mathrm{Na}$ testemunha, onde não houve incorporação de fosfogesso, o acúmulo de sódio foi em torno de $4 \mathrm{meq} / 100 \mathrm{~g}$ de terra ao longo da coluna, enquanto que, no tratamento com $610 \mathrm{mg}$ de fosfogesso, o teor de sódio retido na coluna caiu para uma média de 0,65 meq/100 g de terra (um sexto da testemunha). 
Quadro 2 - Características físicas e químicas das amostras de terra do Latossolo Roxo, distrófico (L.R.) e da Areia Quartzosa (A.Q.) coletadas na camada superficial de 0 a $20 \mathrm{~cm}$ de profundidade.

\begin{tabular}{|c|c|c|c|c|c|c|c|c|c|}
\hline \multicolumn{5}{|c|}{$\%$} & \multicolumn{4}{|c|}{$\mathrm{MEQ} / 100 \mathrm{~g}$ TFSE } & $\mathrm{pH} \mathrm{H}_{2} \mathrm{O}$ \\
\hline L.R. & 22 & 18 & 60 & 1,7 & 2,40 & 0,02 & 5,87 & 8,29 & 5,0 \\
\hline A.Q. & 85 & 1 & 14 & 0,3 & 0,25 & 0,01 & 2,64 & 2,90 & 4,4 \\
\hline
\end{tabular}

Quadro 3 - Quantidades de $\mathrm{Na}^{+}$e Ca ${ }^{+}$retidas nas colunas após passagem do efluente e água de percolação. As colunas de 10 anéis contêm terra tratada com fosfogesso de $0,122,233,488$ e $610 \mathrm{mg}$ nos primeiros 5 anéis.

\begin{tabular}{|c|c|c|c|c|c|c|c|c|c|c|}
\hline \multirow{3}{*}{$\begin{array}{l}\text { Anel } \\
N^{0}\end{array}$} & \multicolumn{4}{|c|}{$\begin{array}{l}\mathrm{Na}^{+} \text {retido na coluna } \\
\text { Fosfogesso, } \mathrm{mg} / 5 \text { anéis }\end{array}$} & \multirow{3}{*}{\multicolumn{2}{|c|}{$\begin{array}{c}610 \\
\mathrm{meq} / 100 \mathrm{~g}\end{array}$}} & \multicolumn{4}{|c|}{$\begin{array}{l}\mathrm{Ca}^{2+} \text { retido na coluna } \\
\text { Fosfogesso, } \mathrm{mg} / 5 \text { anéis }\end{array}$} \\
\hline & 0 & 122 & 244 & 488 & & & 122 & 244 & 488 & 610 \\
\hline & & & & & & & & & & \\
\hline 1 & 4,43 & 4,46 & 3,83 & 2,60 & 2,06 & 3,03 & 5,34 & 7,83 & 6,33 & 8,50 \\
\hline 2 & 4,61 & 3,26 & 2,10 & 1,58 & 0,84 & 3,26 & 5,24 & 6,74 & 11,43 & 11,46 \\
\hline 3 & 3,94 & 2,96 & 2,21 & 8,85 & 0,60 & 3,28 & 5,00 & 6,16 & 11,98 & 11,64 \\
\hline 4 & 3,79 & 3,26 & 1,75 & 0,58 & 0,59 & 3,50 & 4,43 & 6,74 & 9,18 & 9,86 \\
\hline 5 & 3,75 & 3,49 & 1,76 & 0,69 & 0,63 & 4,46 & 4,40 & 6,18 & 6,56 & 8,18 \\
\hline 6 & 3,75 & 3,15 & 0,98 & 0,69 & 0,53 & 3,44 & 4,20 & 5,84 & 6,96 & 7,60 \\
\hline 7 & 3,86 & $3,60^{\circ}$ & 1,31 & 1,11 & 0,54 & 3,84 & 4,14 & 6,13 & 6,68 & 8,44 \\
\hline 8 & 4,09 & 3,49 & 1,39 & 1,15 & 0,63 & 4,40 & 4,28 & 5,66 & 6,94 & 7,94 \\
\hline 9 & 3,71 & 3,49 & 1,20 & 1,14 & 0,81 & 4,30 & 3,88 & 5,83 & 7,10 & 7,00 \\
\hline 10 & 3,56 & 3,08 & 1,65 & 1,15 & 0,81 & 4,33 & 3,86 & 4,80 & 6,43 & 6,44 \\
\hline
\end{tabular}


Quadro 4 - Valores de pH da terra aṕs passagem do efluente e água de percolação atraves das colunas de 10 aneis, contendo terra tratada com fosfogesso de $0,122,244,488$ e $610 \mathrm{mg}$ nos primeiros 5 aneis.

\begin{tabular}{|cccccc|}
\hline \multirow{2}{*}{ Anel } & \multicolumn{5}{c|}{ Fosfogesso, $\mathrm{mg} / 5$ anéis } \\
\cline { 2 - 6 } $\mathrm{n}^{\circ}$ & 0 & 122 & 244 & 488 & 610 \\
\hline 1 & 8,7 & 8,5 & 7,8 & 7,4 & 7,6 \\
2 & 8,4 & 8,1 & 7,6 & 7,0 & 7,7 \\
3 & 8,0 & 7,7 & 7,7 & 6,4 & 6,6 \\
4 & 8,0 & 7,8 & 7,4 & 6,4 & 6,5 \\
5 & 7,8 & 7,6 & 7,5 & 6,6 & 6,6 \\
6 & 7,8 & 7,6 & 7,5 & 6,5 & 6,5 \\
7 & 7,7 & 7,5 & 7,2 & 6,6 & 6,2 \\
8 & 7,6 & 7,4 & 7,1 & 6,5 & 6,1 \\
9 & 7,6 & 7,6 & 7,1 & 6,3 & 6,3 \\
10 & 7,6 & 7,5 & 7,2 & 6,3 & 6,2 \\
\hline
\end{tabular}

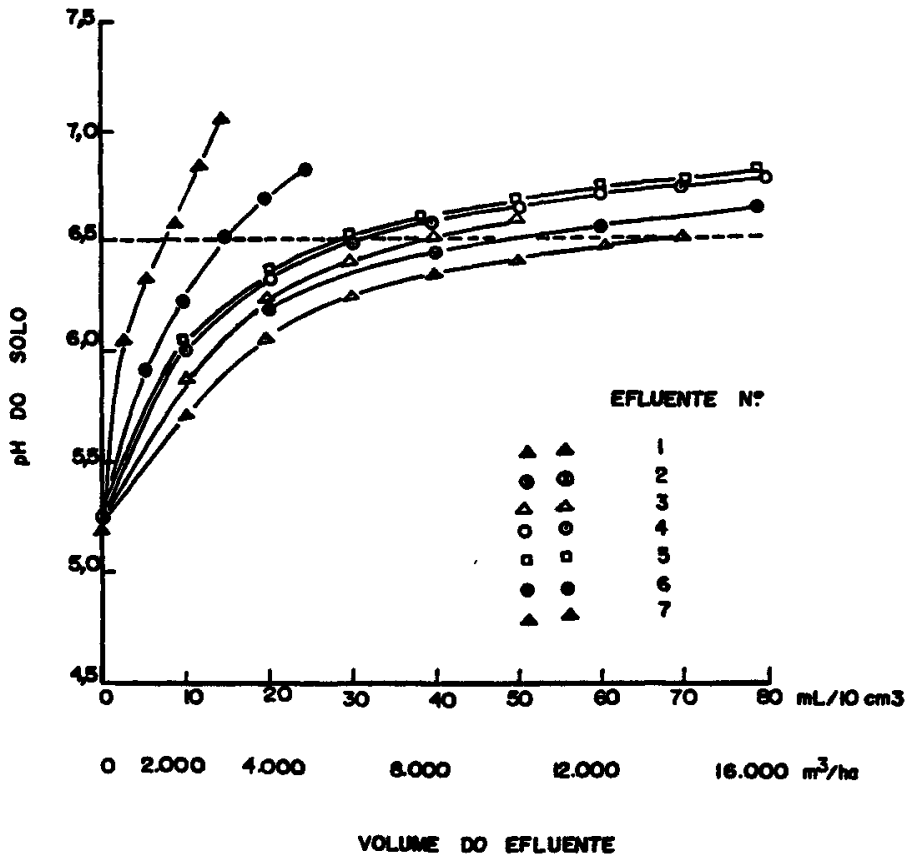

Figura 1 - Curvas de titulação potenciométrica obtidas com efluentes de várias fontes, aplicados na camada superficial (0 a $20 \mathrm{~cm}$ ) do Latossolo Roxo, distrófico. 


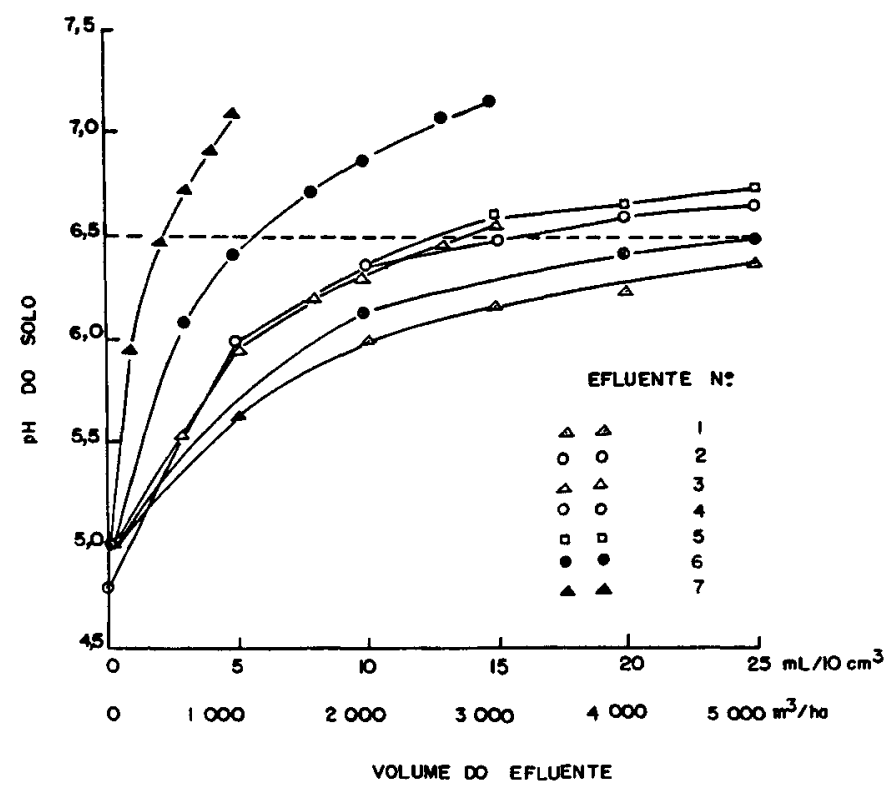

Figura 2 - Curvas de titulação potenciométrica obtidas com efluentes de várias fontes, aplicados na camada superficial (0 a $20 \mathrm{~cm}$ ) da Areia Quartzosa.

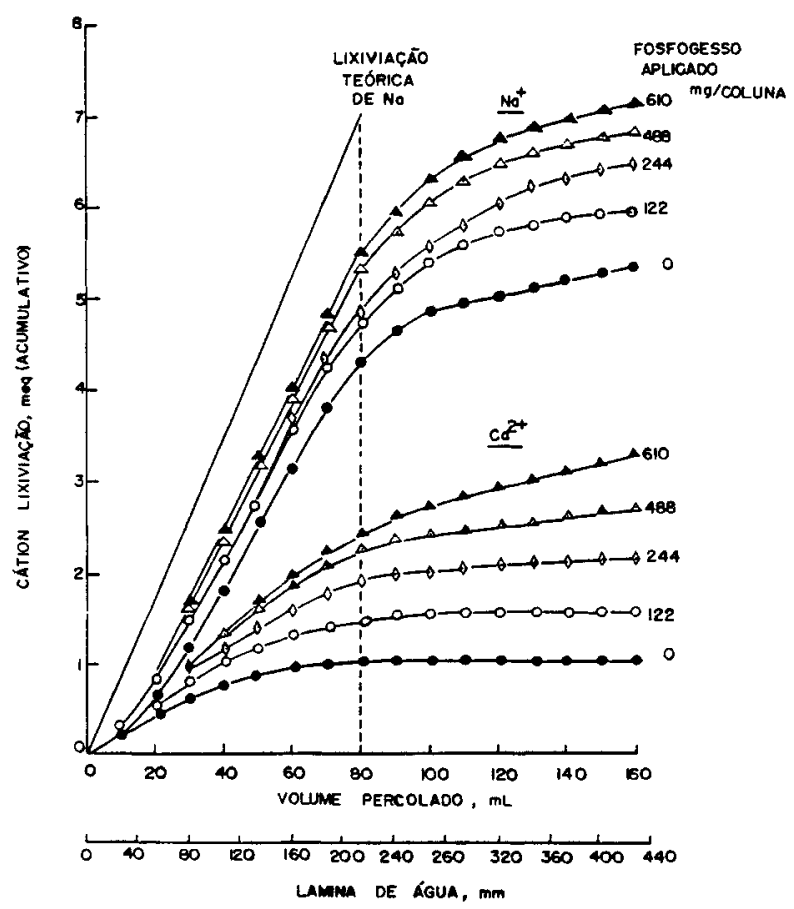

Figura 3 - Lixiviação do sódio e cálcio nas colunas de terra tratadas com $80 \mathrm{ml}$ de efluente, várias quantidades de fosfogesso e percolado em frações de $10 \mathrm{em} 10 \mathrm{ml}$ até atingir o total de $160 \mathrm{ml}$. 
O teor de cálcio na testemunha, após passagem de efluente e água para lixiviação de sódio, ainda é apreciável e corresponde de 40 a $50 \%$ da capacidade de troca de cátions. Com a elevação do nível de fosfogesso aplicado, o teor de cálcio também aumentou atingindo a capacidade de troca de cátions com uma dose de $610 \mathrm{mg} /$ coluna, a dose mais alta do experimento. Neste tratamento, o teor de sódio retido no solo foi consideravelmente reduzido. Segundo estudo de equilibrio de troca catiônica entre sódio e cálcio feito por KINJO \& MARCOS (1982b), a relação sódio cálcio trocáveis diminui linearmente com a diminuição da concentração de sódio em relação a do cálcio da solução do solo. A aplicação de fosfogesso aumenta a concentração de cálcio e, consequentemente, diminui o teor de sódio no solo através do processo de troca catiônica entre sódio e cálcio. Como a série liotrópica indica (FASSBENDER, 1975), o ion sódio é mais fracamente retido que o cálcio pelas cargas negativas dos colóides do solo, facilitando a remoção do sódio pela lixiviação.

A reação do solo mudou com a aplicação de efluente alcalino e variou com as quantidades de fosfogesso incorporados no solo, como mostram os dados apresentados no Quadro 4. Com a aplicação de efluente equivalente a $16.000 \mathrm{~m}^{3} / \mathrm{ha}$ a $20 \mathrm{~cm}$ de profundidade, $\mathrm{o} \mathrm{pH}$ na testemunha atingiu uma faixa de 7.6 a 8.7 , mesmo após passagem de um volume de água igual ao do efluente. À medida que a quantidade de fosfogesso aplicada aumentou, houve a diminuição no $\mathrm{pH}$ a nível adequado para o crescimento das plantas.

Este estudo mostrou que a aplicação de efluente alcalino das fábricas de papel e de celulose corrige a acidez do solo. Há, porém, o risco de acúmulo de sódio no solo a um nível prejudicial ao crescimento de plantas. Este problema pode ser resolvido pela utilização de fosfogesso que facilita a eliminação do sódio adicionado e, ao mesmo tempo, aumenta o cálcio disponível para as plantas.

\section{CONCLUSÃO}

A aplicação de efluente de fábrica de celulose resulta em elevação do $\mathrm{pH}$ do solo. $\mathrm{O}$ volume de efluente necessário para atingir $\mathrm{pH} 6.5$ depende da composição química do efluente e do poder tampão de acidez do solo. A lixiviação de sódio é maior quando o fosfogesso é aplicado ao solo. A combinação de efluente com fosfogesso corrige a acidez do solo, aumenta o teor de cálcio e, ao mesmo tempo, reduz o acúmulo de sódio no solo.

\section{REFERÊNCIAS BIBLIOGRÁFICAS}

ESTADOS UNIDOS. Department of Agriculture. Salinity Laboratory - Staff. Diagnosis and improvement of saline and alkali soils. Washington, 1954. 160p.

FASSBENDER, H.W. Quimica de suelos. Turrialba, IICA, 1975. 398p.

KINJO, T. \& MARCOS, Z.Z. Adsorção de sódio em alguns solos do Estado de São Paulo. I. Isoterma de adsorção de sódio. Revista Brasileira de Ciência do Solo, Campinas, 6:73-77, 1982a.

KINJO, T. \& MARCOS, Z.Z. Adsorção de sódio em alguns solos do Estado de São Paulo. II. Equilibrio de troca catiônica entre sódio e cálcio. Revista Brasileira de Ciência do Solo, Campinas, 6:78-82, 1982a.

Trabalho entregue para publicação em 14.08 .91

Trabalho aprovado para publicação em 16.12.91 